\title{
CZY MOŻE ISTNIEĆ ŚWIAT RZECZYBEZ RZECZY? PROBLEM BADANIA INWENTARZY DÓBR W HISTORII SZTUKI ${ }^{1}$
}

\author{
Opowiadanie - za pośrednictwem słów bądź obrazów - mówi nam, \\ że w świecie rzeczywistym [...] istnieja takie a takie przedmioty i sytuacje. \\ Umberto Eco, Szaleństwo katalogowania ${ }^{2}$
}

Historia sztuki u swych początków nastawiona była na badania atrybucyjne i styloznawcze, a zatem pytaniami, na jakie odpowiadał historyk sztuki, były: kto stworzył, co, kiedy, jak, z czego, dla kogo ${ }^{3}$, a wraz z rozwojem dyscypliny również - dlaczego ${ }^{4}$. Od pytania "dlaczego" można wywieść początki socjokulturowych analiz funkcjonowania sztuki, a od nich daleka jeszcze, ale już prosta droga do nowszych prądów badawczych. Mimo deklarowanego przez przedstawicieli kolejnych „awangard" metodologicznych dystansu do potrzeby osadzania konkretnego dzieła sztuki w epoce, stylu, kręgu artystycznym - do określania autora, daty powstania czy wykorzystanych materiałów - pytania te nigdy nie umilkły. Rzadko zdarza się, by autorzy wykorzystujący „nowe metody" ich nie stawiali, jeśli już samemu nie dochodząc odpowiedzi, to posługując się ustaleniami innych. Można zatem uznać przytoczone kwestie za pytania

${ }^{1}$ Artykuł powstał na podstawie fragmentu pracy magisterskiej napisanej pod kierunkiem prof. dr. hab. Antoniego Ziemby w Instytucie Historii Sztuki Uniwersytetu Warszawskiego w czerwcu 2017 roku: K. Morawski, „"Spis tabellaryczny majątku duchownego należącego do kościoła i klasztoru księży kapucynów w Warszawie przy ulicy Miodowej». Z problematyki badań nad inwentarzami dóbr w historii sztuki”, praca magisterska, 2017, mps, Wydział Historyczny Uniwersytetu Warszawskiego.

${ }^{2}$ U. Eco, Szaleństwo katalogowania, tłum. T. Kwiecień, Poznań 2009, s. 12.

${ }^{3}$ V. Coltman, Material Culture and the History of Art (efacts), w: Writing Material Culture History, red. A. Gerritsen, G. Riello, London 2015, s. 25.

${ }^{4}$ J. Harris, Art History, w: idem, Art History. The Key Concepts, New York 2006, s. 24. 
podstawowe, które, jak się zdaje, ukonstytuowały historię sztuki jako osobną dziedzinę nauki i nie pozwalają zaprzeczyć twierdzeniu, że zajmuje się ona w przeważającej mierze badaniem obiektów, szczególnie w ich warstwie wizualno-estetycznej. Mimo że w wielu przypadkach współczesny historyk sztuki będzie poprzez przedmiot szukał odpowiedzi na różnego rodzaju pytania historyczne i społeczne, to cały czas silne są (a u zarania dyscypliny dominujące były, w czym nurt koneserski w badaniach historyczno-artystycznych faktycznie przypomina archeologię) badania nad samymi obiektami. Dzięki temu historia sztuki wyróżnia się na tle większości nauk humanistycznych, które przedmiot zwykle traktują „,jako obszar inskrypcji, owych metaforycznych substytutów zawsze symbolizujących coś innego, a przede wszystkim to, co społeczne, kulturowe, polityczne itd.” lub „symptom” tychże. W ten sposób w przeszłości zakreślone zostały podstawowe obszary, sposoby działania oraz przedmioty zainteresowania historyka sztuki: prezentowanie za pomocą tekstu obiektów, opowieści o nich oraz stojących za nimi idei.

Historyk sztuki staje zazwyczaj przed materialnym dziełem sztuki i dokonuje jego tekstualizacji ${ }^{6}$, a dopiero w toku pracy dociera do innych tekstów. Co jednak w wypadku, kiedy materialny charakter przedmiotu jest zakryty przez tekst? W jaki sposób historia sztuki może sobie poradzić $z$ badaniem obiektów, których de facto nie ma? Tak pojmowana historia sztuki zmierzyć się musi z problemem badawczym, jakim jest analiza inwentarzy dóbr - specyficznych tekstów niejednokrotnie oderwanych od istniejących przedmiotów, paradoksalnie związanych z nimi bardzo ściśle. Nie można badać inwentarzy bez świadomości referencjalnego charakteru ich treści. Mówią one, że w świecie istnieją lub istniały takie a takie przedmioty - mające swój kształt, wielkość, treść, znaczenie etc. Bezsprzecznie uznać należy zatem, że są one przedmiotem zainteresowania historii sztuki (mimo wszelkich ograniczeń).

Inwentarze dóbr oraz ich analiza w historiografii nierozerwalnie łączą się z edytorstwem źródeł historycznych. Powstało ono głównie w oparciu o osiągnięcia filologów i literaturoznawców, którzy od połowy XIX wieku wydawali drukiem starsze dzieła literackie ${ }^{7}$. Z czasem osiągnięcia językoznawców przyswoiła historia, która edytorstwo źródłowe zaczęła traktować jako naukę pomocniczą. Artykuł Brygidy Kürbisówny z roku 1957 uznać należy za moment przełomowy w namyśle nad wydawaniem źródeł historycz-

5 B. Olsen, Wobronie rzeczy. Archeologia i ontologia przedmiotów, tłum. B. Shallcross, Warszawa 2013, s. 10.

${ }^{6}$ Jas Elsner traktuje całą działalność historyka sztuki jako rodzaj złożonej ekfrazy. J. Elsner, Art History as Ekphrasis, „Art History” 2010, 1(33), s. 10-27; Olsen, W obronie rzeczy..., s. 87-90.

7 J. Lelewel, Nauki dające poznawać źródła historyczne, Poznań 1863. 
nych ${ }^{8}$. Przytoczone przez nią słowa Józefa Siemieńskiego z roku 1922, że „krytyczne wydawanie źródeł historiograficznych jest dotychczas umiejętnością praktyczną, nieopartą na żadnych specjalnych studiach teoretycznych" oraz że „każdego historyka uważa się za powołanego do podejmowania wydawnictw, byle się rozejrzał w wydawnictwach pokrewnych, uważanych za wzorcowe" ${ }^{\prime \prime}$, zdają się niestety rezonować współcześnie ${ }^{10}$. Mimo wzrostu zainteresowania historii sztuki edycjami źródłowymi, a szczególnie wydawaniem inwentarzy dóbr, należy zaznaczyć, że historia sztuki nie wytworzyła własnego namysłu metodologicznego w tym zakresie, a także nie zadała sobie podstawowych, jak się zdaje, pytań o problemy stojące przed badaczem dziejów sztuki zamierzającym poddać analizie inwentarz dóbr. Podjęcie krytycznej refleksji wiąże się z postawieniem pytania, które być może pozostanie na razie otwarte: czy historia sztuki powinna korzystać wyłącznie z osiągnięć historii, czy cele historii sztuki nie uprawniają jej do podjęcia autonomicznego namysłu?

Jerzy Topolski w Teorii wiedzy źródłowe ${ }^{11}$ definiuje źródło historyczne jako podstawę czy też narzędzie do budowania opowieści historyka rekonstruującego minioną rzeczywistość ${ }^{12}$. W tym świetle edycje źródłowe nie jawią się jako roszczące sobie prawo do rekonstrukcji historycznej prawdy, lecz jako - ze względu na opracowanie - dające do niej pełniejszą podstawę. W tej koncepcji ściśle związano źródło z ideą tekstualizacji wiedzy historycznej. „Wszelkie działania intelektualne historyka dokonują się zawsze w świetle jakiejś wiedzy (i wartościowania)"13 - te słowa zaś można traktować jako łącznik między źródłoznawczą a rekonstruktorską działalnością historyka (sztuki). Zasadnicze pytanie padające w kontekście „zwrotu ku rzeczom” i historii kultury materialnej brzmi: jak badać to, co niezachowane? Pojęcia im-material culture i nie-obecności, zdaje się, nie zostały wystarczająco zgłębione w polskiej historiografii artystycznej ${ }^{14}$. Sytuacja analizowania inwentarzy dóbr ob-

${ }^{8}$ B. Kürbisówna, Osiagnięcia i postulaty w zakresie metodologii wydawania źródeł historycznych, „Studia Źródłoznawcze” 1957, 1, s. 53-87.

9 Materiały przygotowane na zjazd historyków polskich, „Przegląd Historyczny” 1922, 23, s. 110-111, za: Kürbisówna, Osiqgnięcia i postulaty..., s. 53.

10 Por. J. Dygdała, Z doświadczeń edytora osiemnastowiecznych lustracji i inwentarzy - czy instrukcja wydawnicza jest w ogóle potrzebna?, w: Teoria a praktyka edycji nowożytnych źródeł w Polsce (XVI-XVIII w.), red. A. Perłakowski, Kraków 2011, s. 143-158.

${ }^{11} \mathrm{~J}$. Topolski, Teoria wiedzy źródłowej, w: idem, Teoria wiedzy historycznej, Poznań 1983, s. 251-277.

12 Ibidem, s. 251-255.

13 Ibidem, s. 251.

${ }^{14}$ Pewien wyjątek stanowić może artykuł Aleksandry Kleśty-Nawrot - jako jedyny w polskiej humanistyce poruszający kwestię badania inwentarzy dóbr w kontekście „zwro- 
razuje twierdzenie Tima Danta o zainteresowaniu rzeczą dopiero w momencie jej braku ${ }^{15}$. W związku z tym, że jednoznaczne połączenie inwentarzowego zapisu z konkretnym zachowanym dziełem sztuki jest w gruncie rzeczy rzadkością, to spis przedmiotów często interesuje historyka sztuki właśnie dlatego, że ich nie ma - w jego badaniach czegoś brakuje albo koniecznie chce on poszerzyć obszar dociekania. Paradoksalnie, z tego samego powodu - braku materialnego przedmiotu - ten typ źródeł go nie interesuje w szerszym zakresie. Ten dojmujący dualizm dostrzegalny w badaniach źródłoznawczych skutkuje słuszną, jak się zdaje, rezerwą, z jaką badacze sztuki podchodzą do inwentarzy dóbr ${ }^{16}$.

Umiejscowienie historii sztuki względem historii kultury materialnej pozwala określić, czym spisy mienia mogą być, a czym nie.

Historia kultury materialnej ma w Polsce długą tradycję. W warunkach powojennych miała być oparta na badaniu „społeczno-technicznej strony produkcji, podziału, wymiany i konsumpcji dóbr materialnych"17. Postulowana historia kultury materialnej miała stać się wyrazicielką filozofii marksistowskiej oraz polem implementowania metod marksizmu-leninizmu do archeologii i etnologii ${ }^{18}$. $Z$ tej perspektywy nie dziwi traktowanie historii sztuki $z$ rezerwą - kultura materialna miała eksplorować marksistowską „nadbudowę” ludowo-robotniczego świata rzeczy, a zatem stanowić niejako odpowiedź na badanie sztuki - rozumianej jako burżuazyjny środek opresji i akumulacji dóbr ${ }^{19}$.

tu ku rzeczom", zob. A. Kleśta-Nawrot, Rzecz i człowiek w XVIII-wiecznych testamentach i inwentarzach kobiecych, w: Rzeczy i ludzie. Humanistyka wobec materialności, red. J. Kowalewski, W. Piasek, M. Śliwa, Olsztyn 2008, s. 375-389; zob. również An Antropology of Absence. Materializations of Transcendence and Loss, red. M. Bille, F. Hastrup, T.F. Sørensen, New York-Dordrecht-Heidelberg-London 2010.

15 T. Dant, Material Culture in the Social World. Values, Activities, Lifestyles, Buckingham 1999, s. 15.

16 O inwentarzach jako przedmiocie badań historyka zob. szczególnie: D. Główka, A. Klonder, Inwentarze w badaniach kultury Europy od średniowiecza po nowożytność, „Kwartalnik Historii Kultury Materialnej” (dalej: KHKM), LI, 2003, 2, s. 157-175; oraz A. Pośpiech, Pułapka oczywistości. Pośmiertne spisy ruchomości szlachty wielkopolskiej z XVII w., Warszawa 1992.

17 K. Majewski, Historia kultury materialnej, KHKM, I, 1953, 1-2, s. 24.

18 Ibidem, s. 22-24.

${ }^{19}$ Co znamienne, wykład $z$ historii kultury materialnej Jerzy Kulczycki prowadził w uczelniach radzieckich jako przedmiot wstępny dla studentów historii sztuki; J. Kulczycki, Założenia teoretyczne dla historii kultury materialnej, KHKM, III, 1955, 3, s. 520. 
Mimo iż to podejście straciło na mocy wraz z końcem stalinizmu ${ }^{20}$, a studia nad kulturą materialną oparte zostały następnie w dużej mierze na badaniach mieszczaństwa i szlachty, to zarysowany na tym wczesnym etapie podział zdaje się funkcjonować do dzisiaj. Przedmiotem zainteresowania historii sztuki miałyby być wytwory kultury mające walory estetyczne i artystyczne (jak pojmowane, tego teoretycy kultury materialnej nie precyzowali), kultura materialna zaś w kręgu swego zainteresowania umieszczała "siły wytwórcze” i elementy życia codziennego „zwykłych ludzi”, z dopuszczalnymi, proponowanymi przez etnografię, badaniami nad sztuką ludową. $Z$ tak sztywnego podziału wynikającego z materializmu historycznego szybko zrezygnowano, bo już w roku 1959 Jerzy Rutkowski pisał, że wszystkie przedmioty, a nie tylko te o charakterze utylitarnym, są polem zainteresowania historyka kultury materialnej ${ }^{21}$. W roku 1971 na łamach „Kwartalnika Historii Kultury Materialnej” opublikowano spis prezentujący zagadnienia, które miały być przedmiotem historii kultury materialnej i które bardzo szeroko zarysowały granice dziedziny ${ }^{22}$. Pozbawione silnej „nadbudowy” ideologicznej, dość swobodnie weszły w obszar historii sztuki ${ }^{23}$. Podobnie historia sztuki z czasem skierowała swoje zainteresowanie na przedmioty codziennego użytku, a następnie na zagadnienia, których badanie wyraża się odejściem od ścisłego przywiązania do obiektu, w czym zaczęła przypominać historię kultury materialnej.

Powyższe uwagi o kulturze materialnej są o tyle istotne, że to właśnie $\mathrm{w}$ ramach tej gałęzi historii najlepiej dostrzegalne jest nieprzerwane zainteresowanie inwentarzami majątku oraz ich edycjami. Jeśli zatem podejmować próbę metodologicznego namysłu nad wykorzystaniem tego typu źródeł w historii sztuki, to tylko w zestawieniu $z$ ugruntowanymi osiągnięciami poprzedników. Umiejscowienie historii sztuki w kontekście badań nad kulturą materialną daje odpowiedź na pytanie o to, dlaczego historiografia artystycz-

${ }^{20}$ Należy zaznaczyć, że jeszcze przed połową lat 50. zdarzały się odstępstwa od takiego podejścia, zob. A. Wyczański, Szlacheckie inwentarze pośmiertne z XVI W. jako źródło do dziejów kultury materialnej w Polsce, KHKM, II, 1954, 4, s. 691-699; zdarzała się również krytyka podstawowych jego założeń, zob. W. Holubowicz, Uwagi o historii kultury materialnej jako nauce, KHKM, III, 1955, 3, s. 563-585.

${ }^{21}$ J. Rutkowski, Historia kultury i próba systematyzacji jej zagadnień, KHKM, VII, 1959,1, s. 3-61.

22 J. Wielowiejski, Próba systematyki kultury materialnej społeczeństw europejskich w starożytności i średniowieczu, KHKM, XIX, 1971, 1, s. 189-191.

${ }^{23}$ Jeszcze w roku 1976 Kazimierz Majewski uważał, że historia sztuki winna raczej należeć do szerokiej historii kultury materialnej i badać rzeczy w ich „aspekcie formalno-plastycznym i znaczeniowym". K. Majewski, Dalsze uwagi o badaniu historii rzeczy, KHKM, XXIV, 1976, 1, s. 109. 
na długo nie darzyła dużym zainteresowaniem tego typu źródeł, a kultura materialna - owszem.

Historia kultury materialnej zajmuje się (a przynajmniej to deklaruje) dziedzinami kultury takimi, jak: uprawa roli, hodowla zwierząt, rzemiosło w znaczeniu utylitarnym (narzędzia, maszyny), handel, transport, budownictwo (początkowo nie architektura, ale $z$ czasem granicę tę zatarto), ubiory czy wyposażenie wnętrz. Jak zatem widać, w większości wypadków jednostkowy charakter opisywanych przedmiotów nie ma większego znaczenia dla badacza kultury materialnej - szczegółowy wygląd grabi z połowy XIX wieku (o ile istnieją choć jedne grabie $z$ tego czasu dające pojęcie o wyglądzie tego narzędzia) nie będzie miał znaczenia w badaniach nad uprawą roli w Królestwie Polskim. Zupełnie inaczej rzecz się ma w historii sztuki pojmowanej jako rozwój przemian stylowych, gdzie niuanse w zmianach wyglądu odgrywają znaczącą rolę. Historia kultury materialnej to w dużej mierze analizy statystyczne posługujące się „typami” przedmiotów, gdzie jednostkowy charakter obiektu nie odgrywa roli dominującej albo zgoła żadnej. Historia kultury materialnej jako problem naukowy postawi istnienie (lub brak) wanny w bogatym domu w początkach XIX wieku ${ }^{24}$, podczas gdy historia sztuki zada pytanie o jej wzorzec formalny i szukać go będzie w antycznym sarkofagu. O ile informację o pierwszej kwestii zdecydowanie łatwo odczytać z inwentarza majątku, o tyle drugą tylko w nielicznych przypadkach. Nie dziwi zatem, że „u podstaw podziału nauk historycznych na poszczególne dziedziny leży m.in. różnica w sposobie wykorzystywania przez nie materiałów źródłowych"25. I chociaż wymyślony przykład antykizowanej wanny wydawać się może karygodnym uproszczeniem, to przestanie nim być, jeśli uświadomimy sobie, że Warburgowski postulat zniesienia policji granicznych między dyscyplinami nigdy w pełni nie przemodelował nauk humanistycznych (pomijając fakt, że historia nie zawsze dobrze pasuje do definicji humanistyki). Stąd zatem wynika różnica w podejściu historii sztuki i historii kultury materialnej do inwentarzy - podstawowe znaczenie dla popularności (lub jej braku w wypadku badań historyczno-artystycznych) edycji źródłowych inwentarzy leży w możliwościach odczytania oczekiwanych w ramach każdej z nauk informacji, co wyjaśniają słowa Kazimierza Majewskiego:

${ }^{24}$ E. Kowecka, Bogaty dom warszawski z początków XIX w. Inwentarz ruchomości pozostałych po Elżbiecie Grabowskiej, KHKM, XXI, 1971, 1, s. 140.

${ }^{25}$ Wypowiedź H. Łowmiańskiego opublikowana w: Dyskusja na posiedzeniu plenarnym Wydziału I Nauk Społecznych Polskiej Akademii Nauk w dniu 2 lutego 1955 roku nad zagadnieniami teoretycznymi historii kultury materialnej, KHKM, III, 1955, 3, s. 590. 
Tak pomyślane badania rzeczy byłyby przede wszystkim badaniami źródłoznawczymi [podkr. - K. Majewski] dla historii różnych dziedzin aktywności ludzkiej (gospodarki, techniki, sztuki, ideologii, religii, sportu itd.) oraz źródłoznawczymi i rekonstruującymi fakty dziejowe dla historii kultury materialnej życia codziennego (mieszkanie, ubiór, pożywienie itd. ${ }^{26}$.

Wyżej zarysowana dychotomia między różnymi spojrzeniami na przedmioty, szczególnie na dzieła sztuki, posłużyć może jako fundament następującego pytania: co historyk sztuki jest w stanie odczytać $z$ inwentarzy mienia? W wypadku obrazów i rzeźb może przede wszystkim poznać tematykę przedstawienia, wynikającą z prostej naoczności, jakiej poddana była osoba spisująca inwentarz. W zależności od rodzaju inwentarza podana jest cena obiektów. W niewielu przypadkach występują nazwiska autorów dzieł, choć zwykle nie można uznać takiej informacji za pewnik, jest ona raczej symptomem pewnej tradycji lub przekonania (co samo w sobie jest cenną informacją). Wreszcie w zależności od typu spisu możliwe bywa zrekonstruowanie rozmieszczenia obiektów we wnętrzu. Niezaprzeczalnie w większości wypadków, dysponując samym inwentarzem bez odpowiedniego materiału porównawczego, b a d a c z przed mi o tów jest w stanie odczytać niewiele albo zgoła nic. W tym należy upatrywać przyczyn długotrwałej wstrzemięźliwości historyków sztuki w korzystaniu z tego typu źródeł, a obecnie obserwowany wzrost zainteresowania nimi tłumaczyć przemianami w podejściu metodologicznym. Im bardziej historia sztuki rozszerza swój obszar studiów poza ścisłe badanie obiektów i zachodzących przemian stylowych, tym większe otwierają się przed nią możliwości wynikające $z$ analiz inwentarzy.

Wymienione ograniczenia wynikają $z$ tekstualnego charakteru inwen$\operatorname{tarzy}^{27}$. Ich spisywanie miało do pewnego momentu znaczenie wyłącznie ekonomiczne - określające wielkość majątku, a ich pełne znaczenie (i pełna czytelność) ujawniało się jedynie w zestawieniu z poddanym skatalogowaniu zbiorem; co więcej - zbiorem w formie, która była przedmiotem spisu. Można zatem zaryzykować stwierdzenie, że żaden historyczny inwentarz lub spis nie opisuje zachowanego do chwili obecnej zbioru, bo wszystkie kolekcje uległy przemianom (dodawaniu i odejmowaniu elementów, rozproszeniom,

${ }^{26}$ Majewski, Dalsze uwagi o badaniu..., s. 110.

27 Napięcie to występuje również na przykład w opisach kolekcji i ekfrazach, a od XVIII wieku również katalogach zbiorów - stanowią one jednak odrębny obszar badań, który nie jest przedmiotem rozważań w niniejszym artykule. 
przemieszczeniu przedmiotów). Inwentarze $z$ założenia są paralelne względem zbioru, z czym wiąże się wątpliwość, czy w przypadku niezachowanej kolekcji granica tekstu inwentarza, a wraz z nią granica językowego pojmowania świata, są możliwe do przekroczenia - dotarcia do przedmiotu. „Skoro człowiek historyczny to człowiek żyjący, pracujący i mówiący, to cała treść Historii bierze się z psychologii, socjologii i nauk o języku"28. W takim ujęciu historia - w całej wieloznaczności tego słowa, w której nauka o przeszłości stanowi de facto opowieść o dziejach - stała się przedmiotem analiz Haydena White'a ${ }^{29}$, głównego teoretyka narratywizmu historycznego ${ }^{30}$. Nie tylko przyięcie perspektywy, według której duża część przejawów ludzkiego życia osadzona jest w słowach, ale również praktyka badania historii (oparta na źródłach pisanych) oraz "tekstualizacja” źródeł materialnych doprowadziły do sytuacji, w której analizie poddawany zostaje efekt określonego użycia języka. Zbliżona konstatacja pozwoliła strukturalistom (i poststrukturalistom) ująć badania nad kulturą w ramy metod wytworzonych przez nauki o języku i przy ich użyciu podjąć refleksję nad zastosowaniem - a w zasadzie nad wytworzeniem - ram, w które da się wpisać elementy sztuki. O ile jednak ponowocześni naukowcy skupiali się raczej na analizowaniu zjawisk zastanych w kulturze, o tyle współcześnie część badaczy próbuje przekroczyć granice i tendencje nakreślone przez poprzedników, proponując nowe perspektywy. I tak na przykład niektóre koncepcje tak zwanej nowej humanistyki tworzą ramy do badań, w których paradygmat antropocentryczny przestaje być dominujący ${ }^{31}$. W ramach tego spojrzenia powstał między innymi „zwrot ku rzeczom", który zdaje się reakcją na konstruktywistyczne oderwanie humanistyki od materialnie istniejącej rzeczywistości ${ }^{32}$, a który w kontekście namysłu

${ }^{28}$ M. Foucault, Słowa i rzeczy. Archeologia nauk humanistycznych, tłum. T. Komendant, Gdańsk 2006, s. 332-333.

${ }^{29}$ H. White, Foucault Decoded. Notes from Underground, „History and Theory” 1973, 1(12), s. 23-54; por. Topolski, Teoria wiedzy..., s. 251-255.

30 Por. H. White, Poetyka pisarstwa historycznego, tłum. E. Domańska, M. Loba, A. Marciniak et al., Kraków 2010; idem, The End of Narrative Historiography, w: Świat historii. Prace z metodologii historii i historii historiografii dedykowane Jerzemu Topolskiemu z okazji siedemdziesięciolecia urodzin, red. W. Wrzosek, Poznań 1998, s. 393-409.

${ }^{31}$ Por. E. Domańska, Historia w kontekście posthumanistyki, „Historyka. Studia Metodologiczne" 2015, 45, s. 5-21 (tam również podstawowa literatura przedmiotu).

32 J. Kowalewski, W. Piasek, W poszukiwaniu utraconej Rzeczywistości. Uwagi na marginesie projektu „zwrot ku rzeczom” w historiografii i archeologii, w: Rzeczy i ludzie..., s. 62. Przede wszystkim chodzi o zerwanie z tendencją do traktowania przedmiotów jedynie jako elementów symbolicznych, przez które „odczytywać” można kryjących się za nimi ludzi i całe kultury, por. E. Domańska, Ku historii nieantropocentrycznej, w: eadem, Historie niekonwencjonalne, Poznań 2006, s. 104-127. Krytykowane podejście widać również 
nad inwentarzami może być szczególnie interesujący. Rozwijanie oraz przyjmowanie nowych metodologii badawczych przez historię sztuki, takich jak "zwrot ku rzeczom”, paradoksalnie skierowało ją na tory wskazane przez Jerzego Kulczyckiego w roku 1955. Historyk sztuki postulował wtedy „badanie użytkowej strony materialnych wytworów" ${ }^{\prime \prime 3}$, co ujawnia się obecnie w tekstach dotyczących sprawczości rzeczy. Prac skupiających się na materialności w humanistyce powstało już wiele, podobnie omówień samego zwrotu ${ }^{34}$. Na potrzeby artykułu wystarczy prosta konstatacja, że współczesna humanistyka w pewnych obszarach w centrum zainteresowania stawia przedmiot w jego materialnym ujęciu, a także wpływ, jaki ten przedmiot ma na człowieka, oraz że w humanistyce wzrasta krytyczny dystans względem narratywizmu i tekstualizacji.

W kontekście tych nowych nurtów badawczych w pełni ujawnia się paradoksalny charakter inwentarza jako źródła historycznego. Inwentarze niosą ze sobą informacje o przedmiotach w ich „osobowym” charakterze, jeśli zatem uznać, że inwentarz jest narzędziem do badania rzeczy, to podstawowy paradoks polega na fakcie „powrotu do rzeczy” przez ich stricte tekstualne odwzorowanie. Mimo że Bjørnar Olsen stoi na stanowisku, iż taka zależność nie wyklucza możliwości upodmiotowienia rzeczy ${ }^{35}$, dla historii sztuki, która od przedmiotów nigdy nie oddaliła się na tyle, by powrót do nich musiał być postrzegany jako wyzwanie, sytuacja dotarcia do materialności poprzez tekst może wydawać się paradoksalna i wymaga szerszego namysłu. Co więcej, przywiązanie do badań „strukturalistycznych”, gdzie aspekty znaczeniowe oraz formalne na równi mogą służyć kategoryzowaniu dzieł sztuki, tworzeniu struktur opartych na relacjach między nimi - od Typenlehre Erwina Panof-

w pracach poświęconych inwentarzom dóbr, gdzie ich analiza postrzegana jest po prostu jako badania kultury, zob. np. E. Mazur, Wykorzystanie inwentarzy w badaniach nad kultura XIX wieku na ziemiach polskich, KHKM, LI, 2003, 2, s. 177-182.

${ }^{33}$ Kulczycki, Założenia teoretyczne..., s. 521.

34 Zob. np. E. Domańska, The Return to Things, „Archeologia Polona” 2006, 44, s. 171-185; M. Krajewski, W stronę socjologii przedmiotów, w: W cywilizacji konsumpcyjnej, red. M. Golka, Poznań 2004, s. 43-64; B. Latour, Nadzieja Pandory. Eseje o rzeczywistości w studiach nad nauką, tłum. K. Abriszewski et al., Toruń 2013.

35 „Co więcej, wbrew odwiecznej tyranii tekstów pisanych i mówionego języka żywię przekonanie, że o rzeczy można też zadbać w tekstach. Nie podpisuję się pod doktryną "przepaści», na której opiera się wiele konstruktywistycznych metod socjologicznych, dowodzących, że rzeczy (i «świat») dzieli od języka niemożliwa do pokonania przepaść, która czyni każde wypowiedzenie wyłącznie językowym konstruktem. Stając po stronie takich autorów, jak Benjamin i Latour, wierzę, że rzeczy zawierają również swoje artykulacje, dające się zarówno przełożyć na język, jak i zapośredniczyć przez środki ekspresji” (Olsen, Wobronie rzeczy..., s. 11). 
skiego po „ciągi form” George'a Kublera ${ }^{36}$ - nie daje pola do szczególnego namysłu nad jednostkowym przedmiotem w oderwaniu od wytworzonych ram. „Zwrot ku rzeczom" pozwolił raczej na namysł nad - przysłoniętym niekiedy między innymi przez powtarzalne schematy badawcze czy tradycję muzealizacji - sensem fizycznie istniejącego przedmiotu, kwestią pierwotnego kontekstu - dotykania, manipulowania przedmiotem, zwielokrotniania i tym podobnymi ${ }^{37}$. Jak się zdaje, postrzeganie związku historii sztuki z rzeczami jako bliższego niż wskazanie, że są one „o tyle ważne, o ile mówią o ludziach, społecznościach i kulturach" ${ }^{\prime 38}$, doprowadziło do mniejszego zainteresowania „zwrotem ku rzeczom” w tej dziedzinie, a co za tym idzie, do zepchnięcia na dalszy plan teoretycznego namysłu nad historią rzeczy i ich "nie-obecnością” - kwestii, które mogłyby otworzyć nowe perspektywy w badaniu dzieł sztuki w ich materialnej i pozamaterialnej warstwie.

Przytoczone we wstępie do tomu Rzeczy i ludzie pytanie, „czy świat rzeczy w ogóle może istnieć bez człowieka?"39, w wypadku prezentowanych paradoksów wiążących się z inwentarzami można zastąpić innym: czy świat rzeczy może istnieć bez rzeczy? Przez co należy rozumieć wątpliwość, czy bez zestawienia $z$ obiektami historyk sztuki może w ogóle prowadzić badania inwentarzy? Oraz to, w jaki sposób, jeśli w ogóle, uchwytne są przedmioty w tekście? Na te pytania starała się odpowiedzieć Catherine Richardson w artykule Written Texts and The Performance of Materiality ${ }^{40}$. Skupiając się na studiach porównawczych, wskazuje na decydującą rolę wyobraźni oraz do-

${ }^{36}$ Por. E. Panofsky, Imago Pietatis. Przyczynek do historii typów przedstawieniowych Mąż Boleści i Maria Pośredniczka, w: idem, Studia z historii sztuki, oprac. J. Białostocki, Warszawa 1971, s. 95-121; G. Kubler, Kształt czasu. Uwagi o historii rzeczy, tłum. J. Hołówka, Warszawa 1970; zob. również inspirujący artykuł Piotra Skubiszewskiego, obrazujący rolę badań strukturalistycznych w historii sztuki i wyraźnie wskazujący na aspekty, które przez długie lata dominowały w historii sztuki: P. Skubiszewski, O dwóch podstawowych sposobach uprawiania historii sztuki, „Teksty: teoria literatury, krytyka, interpretacja" $1974,5(17)$, s. 57-85.

37 Zob. G. Jurkowlaniec, Sprawczość rycin. Rzymska twórczość graficzna Tomasza Tretera i jej europejskie oddziaływanie, Kraków 2017; A. Ziemba, Sztuka Burgundii i Niderlandów 1380-1500, t. 3: Wspólnota rzeczy. Sztuka niderlandzka i północnoeuropejska 1380-1520, Warszawa 2015.

38 Domańska, Ku historii nieantropocentrycznej, s. 109.

39 J. Kowalewski, W. Piasek, M. Śliwa, Wprowadzenie, w: Rzeczy i ludzie..., s. 10.

${ }^{40}$ C. Richardson, Written Texts and the Performance of Materiality, w: Writing Material Culture..., s. 43-58. W tym kontekście wart przywołania jest również niezwykle interesujący artykuł Jerzego Giedymina, który dobrze obrazuje złożoność analizy źródłoznawczej dokonywanej przez historyka: J. Giedymin, Problemy logiczne analizy historycznej, „Studia Źródłoznawcze" 1958, 2, s. 1-39. 
świadczenia badacza. Cytowany już Foucault pisał o „nieważkiej i ruchomej granicy”, gdzie „nauka bratała się z precyzją, a refleksja z obrazem”41 - gdzie precyzja naukowa wiąże się z poznaniem i odwzorowaniem językowym, a jej interpretacja powiązana jest $z$ psychologią. I chociaż Olsen krytykuje zredukowanie rzeczy do "fenomenu kognitywnego doświadczenia przedmiotu”42, to wspomniana paradoksalność inwentarzy pozwala - a właściwie, wobec złożoności problemu, nakazuje - odwołać się do kognitywistyki, co w tym wypadku nie będzie redukcją, a, jak się zdaje, rozszerzeniem możliwości poznawczych. Rzeczy w inwentarzach są przedmiotem ludzkiego doświadczenia w sposób zapośredniczony - przez tekst, a co za tym idzie: możliwe do „interpretacji” jedynie językowo. Z kwestii poznania językowego zaś wynika niewątpliwie, że ewentualne doświadczenie przedmiotu wymienionego w inwentarzu następuje przez pryzmat indywidualnego doświadczenia - psychologicznie. "Jeśli historycy mają dobrze oddać subtelności językowe - pisze Richardson - muszą być dobrze zorientowani w tym, jak język działa i jak wiąże się z doświadczeniem, którego materialność jest tak ważną częścią"43. Autorzy spisów majątku zazwyczaj mieli za zadanie wyłącznie wymienić jego składowe, przy czym wykaz musiał być tak skonstruowany, żeby poszczególne pozycje dało się przyporządkować do konkretnych obiektów, co wynikało z ekonomicznych przesłanek tworzenia tego typu dokumentów. W związku $z$ tym, że inwentarze powstawały w ścisłym kontakcie $z$ opisywanymi przedmiotami, a być może również z uwagi na jedynie częściowo uchwytną współcześnie specyfikę nowożytnego odbioru sztuki w ogóle (a z całą pewnością pisania o niej w dawnej Polsce), prezentacja przedmiotu w tekście następowała zwykle na podstawie prostej naoczności i nie wymagała szczegółowości. Wydaje się, że język inwentarzy należy więc traktować jako czystą referencjalność. Analiza tego typu źródła musi więc być oparta na realiach epoki, a więc również na doświadczeniu autora tekstu oraz elementach językoznawstwa historycznego. A „jeśli w istocie funkcją języka jest nazywanie, to znaczy odsłanianie reprezentacji albo pokazywanie jej jak palcem, jest on wskazówką, a nie sądem ${ }^{\prime 44}$, toteż rozpoznanie możliwości odczytania inwentarza w jego warstwie dotyczącej przedmiotów musi wiązać się z wykorzystaniem elementów kognitywistyki - takich jak psychologia percepcji czy możliwość poznania językowego.

${ }^{41}$ Foucault, Słowa i rzeczy..., s. 90.

42 Olsen, Wobronie rzeczy..., s. 31.

43 „If historians are to do justice to linguistic subteleties, they need to be savvy about how language works and how it might relate to experience, of which materiality is such a crucial aspect" (Richardson, Written Texts..., s. 43).

${ }^{44}$ Foucault, Słowa i rzeczy..., s. 102. 
W związku z ogromnym obszarem zainteresowania tej gałęzi nauki ${ }^{45}$ oraz hermetycznością narzędzi niedostępnych historykowi sztuki, wskazane zostaną jedynie kwestie mogące uzupełnić lub postawić w nowym świetle namysł nad wykorzystaniem spisów dóbr w badaniach historyczno-artystycznych. Kluczowe dla namysłu nad inwentarzami mienia może stać się pojęcie pojęcia oraz jego ściśle informacyjne znaczenie jako „myślowego odzwierciedlenia i całościowego ujęcia istotnych cech przedmiotów czy zjawisk, myślowego odpowiednika nazwy"46, „uogólnionej idei o klasie przedmiotów, atrybutów, zdarzeń lub procesów, które mogą otrzymać jakąś nazwę" ${ }^{\prime 7}$, a także jako abstrakcji konotującej pewne pozytywnie określone znaczenie ${ }^{48}$. Wymienione w inwentarzach opisy lub nazwy nadane przez spisującego, pod którymi kryją się przedmioty, spełniają wszystkie wymogi, by definiować je jako „pojęcia”. W analizowanym typie źródeł zachowana jest „fundamentalna funkcja pojęć: reprezentowanie wiedzy i doświadczenia człowieka w sposób zapewniający odpowiednią ekonomię poznawczą (ujęcie istotnych - zamiast wszystkich cech) $[\ldots]^{\prime \prime 4}$.

W filozofii do czasów Gottloba Fregego ${ }^{50}$ uważano powszechnie, że pojęcie stanowi reprezentację przedmiotu w świecie, a zatem ma czysto referencyjny charakter. Kiedy Arystoteles dokonywał klasyfikacji kategorii i tworzył definicje, to czynił to za pomocą pojęć, ale nie same pojęcia były dla niego istotne, a konstrukcja logiczna, pozwalająca klasyfikować rzeczy ${ }^{51}$. Odejście od dominującego przekonania, że język jest czystym odwzorowaniem, a fakty językowe znajdowały odbicie w rzeczywistości i przez nią były postrzegane, widać już wyraźnie u Nietzschego ${ }^{52}$, ale dopiero Frege opisał pojęcie jako funkcję sensu i znaczenia ${ }^{53}$. Jego zdaniem, nazwa wyraża swój sens, oznacza

45 Por. Przewodnik po kognitywistyce, red. J. Bremer, Kraków 2016.

46 [Hasło:] Pojęcie, w: Słownik języka polskiego, red. W. Doroszewski, Warszawa 1964, t. 6 , s. 818 .

${ }^{47}$ J. Bremer, A. Chuderski, Pojęcia jako przedmiot badań interdyscyplinarnych, w: Pojęcia, red. J. Bremer, A. Chuderski, Kraków 2011, s. 7.

48 A. Gemel, Językowy model poznania. Kognitywne komponenty w kontynentalnej filozofii języka, Łódź 2015, s. 171.

49 Bremer, Chuderski, Pojęcia jako przedmiot badań..., s. 7.

${ }^{50}$ Frege był przedstawicielem filozofii analitycznej, stała się ona niejako podstawą dla kognitywistyki, por. R.B. Brandom, Jak filozofia analityczna zawiodła kognitywistyke, „Przegląd Filozoficzny. Nowa Seria” 2013, 2(22), s. 17-40.

${ }^{51}$ Por. Arystoteles, Kategorie, w: idem, Dzieła wszystkie, tłum. K. Leśniak, Warszawa 1990 , t. 1, s. 32-63.

52 Gemel, Językowy model poznania..., s. 169.

53 G. Frege, Funkcja i pojęcie, w: idem, Pisma semantyczne, Warszawa 2014, s. 18-44. 
zaś znaczenia ${ }^{54}$, co na jaskrawym przykładzie "krzyża palmowego” wymienionego w pochodzącym z roku 1858 spisie dóbr klasztoru księży kapucynów w Warszawie ${ }^{55}$ należy rozumieć w taki sposób: sensem zapisu „drzewo palmowe w imitacji krzyża z figurą na nim Pana Jezusa" jest krucyfiks jako symbol męki i zbawczego działania Jezusa Chrystusa, a jego znaczeniem jest jednostkowy i fizycznie istniejący w świecie krzyż o nietypowej formie. Opierając się na tym przykładzie, łatwo wywieść, że dla badacza inwentarzy dostępna jest w zasadzie wyłącznie warstwa sensu, nie zaś znaczenia. Ta druga pozostaje jedynie sferą wyobraźni i domysłów, szczególnie jeśli niemożliwe jest odniesienie przedmiotu do rzeczywistości. Można zatem przyiąć, że dla osoby spisującej dokument nadane rzeczy określenie jest pojęciem i ma bardzo konkretne znaczenie osadzone w naocznej rzeczywistości. Co więcej, opisy zawarte $\mathrm{w}$ inwentarzu wpisują się w przytoczone definicje pojęć, bo odwołują się do cech najistotniejszych (forma krzyża, informacja o figurze, kształt palmy), problem pojawia się dopiero w momencie namysłu nad tym, co jest ważne dla różnych grup. Czy dla historyka sztuki istotne będzie to samo, co dla zakonnika? Czy istotność pewnych cech jest jednakowa dla osób żyjących w XIX i XXI wieku? Odpowiedź jest jednoznacznie przecząca i na niej opiera się bariera, jaką napotyka historyk badający inwentarze. „Myślowo rzeczy doświadczane są już jako (uprzednio) opatrzone etykietami i otoczone warstwami językowego znaczenia"56 - podwójne „uprzednie opatrzenie etykietami”, przez spisującego inwentarz i badacza, gdzie ten drugi traktuje swoją etykietę jako dekodującą etykietę pierwszego, może być barierą nie do pokonania, która za Haydenem White'em każe spojrzeć na naukę jako literaturę.

Proces analizy inwentarzy rozpatrywać można również w kontekście dotyczącej kategoryzowania pojęć oraz ich reprezentowania w świadomości teorii

54 Por. A. Derra, Podstawowe pojęcia fregowskiej semantyki. Frege jako ojciec współczesnej filozofii języka, „Studia Semiotyczne” 2007, 26, s. 263-277.

55 „Drzewo palmowe w imitacji krzyża z figurą na nim Pana Jezusa, wszystko drewniane", Archiwum Główne Akt Dawnych w Warszawie, Centralne Władze Wyznaniowe Królestwa Polskiego, nr 190, Akta majątku kościoła i klasztoru księży kapucynów w Warszawie, przy ul. Miodowej N. 494, sygn. 879, s. 75. Krzyż do tej pory znajduje się w klasztorze księży kapucynów, o tym nietypowym motywie ikonograficznym zob. S. Michalczuk, Ukrzyżowanie na palmie jako nowy nieznany typ krucyfiksu barokowego, „Biuletyn Historii Sztuki” XXV, 1963, 1, s. 22-33; oraz niewolna od braków warsztatowych praca N. Kucia-Szymor, Ukrzyżowany na palmowym drzewie. Konserwacja rzeźby drewnianej polichromowanej „Chrystus Ukrzyżowany na drzewie palmowym” z kościoła oo. Dominikanów w Lublinie na tle ikonografii przedstawienia, Kraków 2016.

56 Olsen, W obronie rzeczy..., s. 92. 
egzemplarzy, zaprezentowanej przez Douglasa Medina i Marguerite Schaffer ${ }^{57}$. Każde pojęcie ma wiele "egzemplarzy”, czyli bardziej lub mniej odpowiadających mu przedmiotów, których zbiór dostępny człowiekowi zależy nie tylko od ilości napotkanych obiektów danego typu, ale również od przeprowadzonych uprzednio kategoryzacji. Na takiej podstawie człowiek jest w stanie przyporządkować różne pojęcia do odpowiednich grup, a następnie odwzorować w wyobraźni, opierając się na nabytych wcześniej doświadczeniach. Podstawowym problemem badawczym w tym przypadku staje się pytanie, w jaki sposób człowiek przyporządkowuje nowe egzemplarze do istniejących pojęć oraz pojęcia do egzemplarzy ${ }^{58}$. Kategoryzowanie obiektów następuje poprzez (nieuświadamiane) określenie liczby egzemplarzy, do których są podobne, oraz (co równie ważne) tych, od których się różnią. W związku z tym przedmioty typowe - czyli podobne do dużej liczby egzemplarzy - będą kategoryzowane szybko i z lepszym skutkiem. Trudniej odwzorowywać przedmioty bardzo ogólne oraz bardzo szczegółowe. „Drzewo palmowe w imitacji krzyża” szybko zostanie przyporządkowane do grupy „krzyże”, ale przypisanie go do grupy "krzyże w formie palmy” może skończyć się niepowodzeniem lub błędem $z$ racji małej liczby egzemplarzy podobnych, tak jak i przypisanie go do „obiektów kultu” nie przyniesie odpowiedniego odwzorowania z powodu zbyt dużego zakresu zbioru. Teoria egzemplarzy bardzo dobrze wpisuje się w funkcjonujące przekonanie o dużym znaczeniu nabytego wcześniej doświadczenia w procesie badania inwentarzy dóbr ${ }^{59}$.

Kategoryzowanie przedmiotów i zjawisk, które umożliwia bardziej precyzyjne interpretowanie, w omawianym zagadnieniu głównie słów, ale również przedmiotów, związane jest przede wszystkim z-by zaznaczyć zbieżność z pojęciami - „ujęciem istotnych - zamiast wszystkich - cech” przedmiotu. Badanie cech kluczowych w poznaniu językowym skutkowało przyjęciem wywodzącego się z nauk matematycznych terminu "niezmiennik”, oznaczającego cechę obiektu, która w wyniku przekształcenia pozostaje niezmienna - przykładem pozamatematycznym może być biologiczny mechanizm pozwalający na zachowanie świadomości danego kształtu mimo zmiany perspektywy ${ }^{60}$. W wypadku inwentarzy można niezmienniki wiązać z wcześniej wspomnianą teorią egzemplarzy, gdyż w pojmowaniu pojęcia ważna okazuje się rola cechy niezmiennej, przyporządkowanej do danej kategorii egzemplarzy. Posłu-

57 D. Medin, M. Schaffer, Context Theory of Classification Learning, „Psychological Review" 1978, 85, s. 207-238.

58 Bremer, Chuderski, Pojęcia jako przedmiot badań..., s. 21.

59 Richardson, Written Texts..., s. 44-49.

${ }^{60}$ R. Piłat, Realizm pojęć, w: Pojęcia, s. 48. 
gując się ponownie przykładem krucyfiksu w kształcie palmy znajdującym się w kościele Kapucynów, można wykazać, w jaki sposób na odczytanie zapisów zawartych w inwentarzach wpływ może mieć psychologia. W zdaniu „drzewo palmowe w imitacji krzyża z figurą na nim Pana Jezusa" krzyż z figurą Pana Jezusa staje się grupą egzemplarzy łatwą do kategoryzacji w postaci pojęcia krucyfiksu. W krucyfiksie zaś wskazać można dwa niezmienniki - jako krzyż musi mieć dwa poprzeczne względem siebie odcinki oraz musi być przybita do niego figura Chrystusa ${ }^{61}$. Wyobrażenie tego przedmiotu na podstawie opisu inwentarzowego oraz w oparciu o kategorię niezmienników przynosi prawdopodobnie skutek nieodpowiadający rzeczywistości, gdyż wymieniony obiekt nie ma poprzecznej belki, a dłonie Jezusa przybite są do liści palmy (cały krzyż w zasadzie bardziej jest liściem niż drzewem palmowym).

Badanie przedmiotów pojmowane jest niekiedy na zasadzie przeciwstawienia wykluczających się: antropologicznego „powrotu do rzeczy” oraz strukturalizmu i kognitywizmu ${ }^{62}$. Takie podejście w kontekście inwentarzy dóbr staje się niewystarczające i postulować należy raczej model hybrydyczny, gdzie obszary te nie są tożsame, ale łączą się w ramach szerokiego namysłu dotykającego kategorii językowych i tekstualnych.

Przedstawione odniesienia do historii kultury materialnej, do krytyki tekstualizacji humanistyki oraz do elementów kognitywistyki wskazują jasno, jak obszerny temat pod względem metodologicznym stanowi badanie inwentarzy mienia. Problem przedstawienia dzieł sztuki w inwentarzach dóbr jest przedmiotem zainteresowania historii sztuki jedynie w sposób ogólny. Mimo to wypracowane przez historyków sztuki sposoby postępowania, oparte co prawda na niewyartykułowanym i w większości intuicyjnym pojmowaniu ograniczeń, zdają się znajdować uzasadnienie w przedstawionych metodach. „Język [...] okazuje się bardzo ubogim narzędziem przyswajania znaczeń rzeczy. Wiąże się to z cechą pozawerbalnych form znaczenia [...], w których wykorzystuje się rzeczy - że znaczą one w kontekstach innych elementów, a nie w izolacji lub w związkach o charakterze heterogenicznym" ${ }^{\prime 63}$. Należy jednak zauważyć, że nie chodzi jedynie o kontekst, ale również o niewyrażony (może niewyrażalny) w języku zespół cech przedmiotu. W związku z tym history-

${ }^{61}$ Etymologicznie rzecz biorąc, krucyfiks to crucifixus, co znaczy 'ukrzyżowany', a więc krucyfiks to sama figura Chrystusa; ale skoro jest on „ukrzyżowany”, tj. przybity do krzyża, to i ów krzyż powinien być niezmiennikiem pojęcia.

62 J. Barański, Świat rzeczy. Zarys antropologiczny, Kraków 2007, s. 15.

63 Ibidem, s. 170. 
cy mieli świadomość konieczności szerokiej analizy podczas badania źródeł, $\mathrm{w}$ tym inwentarzy. Wiąże się to $\mathrm{z}$ badaniami hermeneutycznymi w historii - objaśnianiem i interpretowaniem przez szeroki dobór materiału informacyjnego i porównawczego ${ }^{64}$. Zdaje się jednak, że na pytanie postawione przez Hansa Georga Gadamera: „czy wobec tego nadal istnieje możliwość dotarcia do sensu artefaktów nie tylko z naszej, ale również cudzej i odleglejszej przeszłości?" 65 - nie można udzielić jednoznacznej odpowiedzi. O ile szeroko pojęta hermeneutyczność - badanie szczegółu przez ogół, a ogółu przez szczegół - wydaje się jedyną szansą analizy inwentarzy, to już możliwość skutecznego rekonstruowania prawdy historycznej w ten sposób jest dyskusyjna. Szczególnie jeśli rekonstrukcji podlegają istniejące w określonym momencie i w określonych formach przedmioty. Słuszność takiego podejścia potwierdzają również niektóre obszary badań kognitywistyki. „Znajomość konwencjonalnego znaczenia wypowiedzianych słów nie wystarcza do ustalenia pierwotnego znaczenia wypowiedzi [...]"66 - dlatego właśnie historyk sztuki zwykle korzysta $z$ metod porównawczych oraz wskazuje pewne analogie, by źródło historyczne mogło posłużyć do opisu zjawisk. Z inwentarzy dóbr można wyciągać wnioski natury antropologicznej - której w tym wypadku blisko do kultury materialnej - i przyjąć, że dany przedmiot, dany zbiór przedmiotów albo ich wzajemna relacja wskazuje na określone znaczenia (przedmiot jako atrybut władzy, element ostentacji, praktyczne narzędzie...). Jednocześnie niektóre ograniczenia są dla historii sztuki niemożliwe do pokonania, choć i tu zależy to od celów badawczych. Kwestia ta znacznie wychodzi poza ramy namysłu nad metodologią stosowaną w badaniach źródłowych i ociera się o pytanie o charakter samej historii sztuki.

Potrzeba prezentacji materiałów źródłowych, stanowiących konieczną podstawę do badań nad polską sztuką nowożytną, jest swego rodzaju aksjomatem, choć jednocześnie w ostatnich latach praktyka publikacji źródeł (właściwie poza wydawnictwami inwentaryzacyinymi) została zarzucona, a materiały archiwalne w opracowaniach o charakterze problemowym są przytaczane w najlepszym razie tylko w niewielkim wyborze. Należy jednak pamiętać (i przypominać), że teksty te stanowią niezastąpioną podstawę do analiz szczegółowych, także na przykład do rekonstrukcji budowli i ich układu funkcjonalnego (nie wspominając już o kwe-

${ }^{64}$ M. Budzanowska, Morbus hermeneuticus. Wyzwanie współczesnej humanistyki, „Collectanea Philologica" 2011, 14, s. 93.

${ }^{65}$ H.G. Gadamer, Estetyka i hermeneutyka, w: idem, Rozum, słowo, dzieje. Szkice wybrane, tłum. M. Łukasiewicz, K. Michalski, Warszawa 1979, s. 120.

${ }^{66}$ M. Witek, Koncepcja pojęć ad hoc jako wytworów interpretacji aktów komunikacyinych. Analiza krytyczna, w: Pojęcia, s. 139. 
stiach stricte artystycznych). Trzeba też mieć w pamięci słowa, jakie Gębarowicz napisał we wstępie do swej książki, nie straciły one bowiem nic na aktualności: "rzeczowe inwentarze $[\ldots]$ zatracają charakter odbicia indywidualnych tylko upodobań; [...] nabierają cech typowych i stają się przekrojem przez obyczajowość odnośnej epoki i środowiska" ${ }^{167}$

- te słowa Andrzeja Betleja są dobrym przykładem próby zmierzenia się z problemem edycji źródłowej oraz analizy inwentarza w badaniach historii sztuki. Praktyka serii „Materiały do dziejów sztuki i kultury XVII i XVIII wieku”, z pierwszego tomu której pochodzi przytoczony cytat, pokazuje, że współczesna historia sztuki wykorzystuje tylko narzędzia przed laty wypracowane przez historię ${ }^{68}$. Choć należy zaakcentować raz jeszcze, że tego typu działanie ma pewne uzasadnienie wynikające $z$ istotowych podstaw inwentarzy.

Historia sztuki nie zadała sobie pytań podstawowych: o istotę źródła pisanego w badaniach nad niezachowaną sztuką, o znaczenie pojęcia w dotarciu do przedmiotu poddanego wielopoziomowej tekstualizacji. W toczącej się dyskusji ${ }^{69}$ dotyczącej zasadniczych kwestii dla źródłoznawstwa i edycji źródłowych głos historii sztuki nie jest reprezentowany.

${ }^{67}$ A. Betlej, Słowo wstępne, w: Pałac w Wiśniowcu w świetle inwentarzy staropolskich, oprac. A. Betlej, A. Dworzak, A. Markiewicz, Kraków 2016, s. 5; we fragmencie zacytowano: M. Gębarowicz, Materiały źródłowe do dziejów kultury i sztuki XVI-XVIII W., Wrocław-Warszawa 1973, s. 5.

${ }^{68}$ Przykładem konsekwentnie realizowanego projektu wydawania źródeł są publikowane od roku 1994 pod redakcją Jana Ostrowskiego Materiały do dziejów sztuki sakralnej na ziemiach wschodnich dawnej Rzeczypospolitej. W roku 2016 w Instytucie Historii Sztuki UJ powstała wspomniana seria wydawnicza pod redakcją Andrzeja Betleja Materiały do dziejów sztuki i kultury XVII i XVIII wieku, w której do tej pory ukazało się pięć tomów edycji źródłowych. Warto wspomnieć również o wydawanych przez Agnieszkę Perzanowską inwentarzach katedry krakowskiej: Inwentarze katedry krakowskiej z lat 1586, 1620, 1692, oprac. A. Perzanowska, Kraków 2014; Inwentarze skarbca katedry krakowskiej z lat 1702, 1761 i 1791, oprac. A. Perzanowska, Kraków 2017.

${ }^{69}$ Współcześnie daje się zauważyć powrót do zainteresowania samą istotą źródła historycznego oraz edycji źródłowej, zapoczątkowany być może artykułem Piotra Dymmla, P. Dymmel, Edytorstwo historyczne - stan i potrzeby, w: Pamiętnik XV Powszechnego Zjazdu Historyków Polskich, t. 1, cz. 2, red. J. Staszewski. Gdańsk-Toruń 1995, s. 259271. Namysł nad istotą edycji źródłowej najpełniej wyrażony został w pierwszym kompleksowym podręczniku do edycji historycznej: J. Tandecki, K. Kopiński, Edytorstwo źródeł historycznych, Warszawa 2014 (tam też zebrana obszerna literatura dotycząca tematu od narodzin edytorstwa historycznego do współczesności). Pojawiły się również publikacje przekrojowe, analizujące realia wydawania źródeł, por. Teoria a praktyka edycji nowożytnych źródeł w Polsce (XVI-XVIII w.), red. A. Perłakowski, Kraków 2011. 
Niektóre artefakty (w tym dzieła sztuki) przetrwały i stanowią podstawę badań, ale dużo więcej przedmiotów nie zachowało się do współczesności i mogą funkcjonować w badaniach historycznych jedynie w ramach rozpatrywania ich w odniesieniu do zachowanych obiektów ${ }^{70}$. W tym kontekście refleksja na temat historii kultury materialnej i „powrotu do rzeczy" zdaje się wkraczać w nowy etap, związany z rozwojem narzędzi nowej humanistyki. W Polsce pewne elementy omawianego problemu dostrzegane były już w latach 50. - w obu przypadkach można wyciągnąć podobne i, jak się wydaje, zdroworozsądkowe wnioski z dyskusji: historia kultury materialnej jest metadyscypliną, w której istnieje miejsce dla historii, historii sztuki, etnologii itp. ${ }^{71}$ Czy zatem może istnieć świat rzeczy bez rzeczy? Logika każe zaprzeczyć, ale dotychczasowa praktyka badań inwentarzy dóbr wskazuje na inną odpowiedź, wynikającą z faktu rekonstrukcji rzeczywistości, w której słowa tak ściśle wiąże się z rzeczami, a badacze „wytwarzają" świat rzeczy w toku analizy. Perspektywa statystyczno-porównawcza badania inwentarzy, tak mocno zakorzeniona w badaniach historycznych (choć niekoniecznie odpowiadająca podstawowym założeniom historii sztuki), wydaje się w tej chwili najbezpieczniejsza i prawdopodobnie najbardziej owocna, niestety prowadzi niekiedy do nieuprawnionych interpretacji. Nasuwa się jednak wątpliwość, czy takie podejście jest satysfakcjonujące dla historii sztuki, akcentującej swą odrębność względem historii. Obecna sytuacja mnogości założeń metodologicznych oraz zmian zachodzących w naukach humanistycznych, być może również w aspekcie wiedzy źródłoznawczej (szczególnie w jej wąskim wycinku, jakim są inwentarze dóbr), wymaga namysłu. Wnioskowanie z opisów przedmiotów zawartych w inwentarzach ma w dużej mierze charakter abdukcyjny tworzenia na podstawie niewielkiej liczby informacji najbardziej prawdopodobnych wyjaśnień ${ }^{72}$. Czy taki charakter interpretacji należy uznać za optymalny i niemożliwy do przekroczenia? Pytanie to, podobnie jak inne kwestie postawione w artykule, być może zakrawa o namysł nad fundamentami badania historyczno-artystycznego, jednak pewne jest, że przedstawienie tych wątpliwości można uznać za jeden z kroków prowadzących do dalszego rozwoju dyscypliny.

70 A. Gerritsen, G. Riello, Introduction. Writing Material Culture History, w: Writing Material Culture..., s. 8.

${ }^{71}$ Coltman, Material Culture and the History..., s. 20-22.

72 Barański, Świat rzeczy..., s. 105-107. 


\section{BIBLIOGRAFIA}

An Antropology of Absence. Materializations of Transcendence and Loss, red. M. Bille, F. Hastrup, T.F. Sørensen, New York-Dordrecht-Heidelberg-London 2010

Archiwum Główne Akt Dawnych w Warszawie, Centralne Władze Wyznaniowe Królestwa Polskiego, nr 190, Akta majątku kościoła i klasztoru księży kapucynów w Warszawie, przy ul. Miodowej N. 494, sygn. 879

Arystoteles, Kategorie, w: idem, Dzieła wszystkie, tłum. K. Leśniak, Warszawa 1990, t. 1, s. 32-63

Barański J., Świat rzeczy. Zarys antropologiczny, Kraków 2007

Brandom R.B., Jak filozofia analityczna zawiodła kognitywistyke „Przegląd Filozoficzny. Nowa Seria" 2013, 2(22), s. 17-40

Bremer J., A. Chuderski, Pojęcia jako przedmiot badań interdyscyplinarnych, w: Pojęcia, red. J. Bremer, A. Chuderski, Kraków 2011, s. 7-45

Budzanowska M., Morbus hermeneuticus. Wyzwanie współczesnej humanistyki, "Collectanea Philologica" 2011, 14, s. 91-103

Coltman V., Material Culture and the History of Art(efacts), w: Writing Material Culture History, red. A. Gerritsen, G. Riello, London 2015, s. 17-32

Dant T., Material Culture in the Social World. Values, Activities, Lifestyles, Buckingham 1999

Derra A., Podstawowe pojęcia fregowskiej semantyki. Frege jako ojciec współczesnej filozofii języka, „Studia Semiotyczne” 2007, 26, s. 263-277

Domańska E., Ku historii nieantropocentrycznej, w: eadem, Historie niekonwencjonalne, Poznań 2006, s. 104-127

Domańska E., The Return to Things, „Archeologia Polona” 2006, 44, s. 171-185

Domańska E., Historia w kontekście posthumanistyki, „Historyka. Studia Metodologiczne" 2015, 45, s. 5-21

Dygdała J., Z doświadczeń edytora osiemnastowiecznych lustracji i inwentarzy - czy instrukcja wydawnicza jest w ogóle potrzebna?, w: Teoria a praktyka edycji nowożytnych źródeł w Polsce (XVI-XVIII w.), red. A. Perłakowski, Kraków 2011, s. $143-158$

Dymmel P., Edytorstwo historyczne - stan i potrzeby, w: Pamiętnik XV Powszechnego Zjazdu Historyków Polskich, t. 1, cz. 2, red. J. Staszewski. Gdańsk-Toruń 1995, s. 259-271

Dyskusja na posiedzeniu plenarnym Wydziału I Nauk Społecznych Polskiej Akademii Nauk w dniu 2 lutego 1955 roku nad zagadnieniami teoretycznymi historii kultury materialnej, „Kwartalnik Historii Kultury Materialnej” III, 1955, 3, s. $586-620$

Eco U., Szaleństwo katalogowania, tłum. T. Kwiecień, Poznań 2009

Elsner J., Art History as Ekphrasis, „Art History” 2010, 1(33), s. 10-27

Foucault M., Słowa i rzeczy. Archeologia nauk humanistycznych, tłum. T. Komendant, Gdańsk 2006

Frege G., Funkcja i pojęcie, w: idem, Pisma semantyczne, Warszawa 2014, s. 18-44

Gadamer H.G., Rozum, słowo, dzieje. Szkice wybrane, tłum. M. Łukasiewicz, K. Michalski, Warszawa 1979 
Gemel A., Językowy model poznania. Kognitywne komponenty w kontynentalnej filozofii języka, Łódź 2015

Gerritsen A., G. Riello, Introduction. Writing Material Culture History, w: Writing Material Culture History, red. A. Gerritsen, G. Riello, London 2015, s. 1-16

Gębarowicz M., Materiały źródłowe do dziejów kultury i sztuki XVI-XVIII w., Wrocław-Warszawa 1973

Giedymin J., Problemy logiczne analizy historycznej, „Studia Źródłoznawcze” 1958, 2, s. $1-39$

Główka D., A. Klonder, Inwentarze w badaniach kultury Europy od średniowiecza po nowożytność, „Kwartalnik Historii Kultury Materialnej” LI, 2003, 2, s. $157-$ 175

Harris J., Art History, w: idem, Art History. The Key Concepts, New York 2006, s. 2325

Holubowicz W., Uwagi o historii kultury materialnej jako nauce, „Kwartalnik Historii Kultury Materialnej" III, 1955, 3, s. 563-585

Jurkowlaniec G., Sprawczość rycin. Rzymska twórczość graficzna Tomasza Tretera i jej europejskie oddziaływanie, Kraków 2017

Kowecka E., Bogaty dom warszawski z poczatków XIX w. Inwentarz ruchomości pozostałych po Elżbiecie Grabowskiej, „Kwartalnik Historii Kultury Materialnej” XX, 1972, 1, s. 131-141

Krajewski M., W stronę socjologii przedmiotów, w: W cywilizacji konsumpcyjnej, red. M. Golka, Poznań 2004, s. 43-64

Kubler G., Kształt czasu. Uwagi o historii rzeczy, tłum. J. Hołówka, Warszawa 1970

Kucia-Szymor N., Ukrzyżowany na palmowym drzewie. Konserwacja rzeźby drewnianej polichromowanej „Chrystus Ukrzyżowany na drzewie palmowym” z kościoła oo. Dominikanów w Lublinie na tle ikonografii przedstawienia, Kraków 2016

Kulczycki J., Założenia teoretyczne dla historii kultury materialnej, „Kwartalnik Historii Kultury Materialnej" III, 1955, 3, s. 519-562

Kürbisówna B., Osiagnięcia i postulaty w zakresie metodologii wydawania źródeł historycznych, „Studia Źródłoznawcze” 1957, 1, s. 53-87

Latour B., Nadzieja Pandory. Eseje o rzeczywistości w studiach nad nauka, tłum. K. Abriszewski et al., Toruń 2013

Lelewel J., Nauki dające poznawać źródła historyczne, Poznań 1863

Majewski K., Dalsze uwagi o badaniu historii rzeczy, „Kwartalnik Historii Kultury Materialnej" XXVI, 1976, 1, s. 109-115

Majewski K., Historia kultury materialnej, „Kwartalnik Historii Kultury Materialnej” I, 1953, 1-2, s. 3-27

Mazur E., Wykorzystanie inwentarzy w badaniach nad kultura XIX wieku na ziemiach polskich, „Kwartalnik Historii Kultury Materialnej” LI, 2003, 2, s. 177182

Medin D., M. Schaffer, Context Theory of Classification Learning, „Psychological Review" 1978,85 , s. 207-238

Michalczuk S., Ukrzyżowanie na palmie jako nowy nieznany typ krucyfiksu barokowego, „Biuletyn Historii Sztuki” XXV, 1963, 1, s. 22-33 
Olsen B., W obronie rzeczy. Archeologia i ontologia przedmiotów, tłum. B. Shallcross, Warszawa 2013

Panofsky E., Imago Pietatis. Przyczynek do historii typów przedstawieniowych Mą̇ Boleści i Maria Pośredniczka, w: idem, Studia z historii sztuki, oprac. J. Białostocki, Warszawa 1971, s. 95-121

Pałac w Wiśniowcu w świetle inwentarzy staropolskich, oprac. A. Betlej, A. Dworzak, A. Markiewicz, Kraków 2016

Piłat R., Realizm pojęć, w: Pojęcia, red. J. Bremer, A. Chuderski, Kraków 2011, s. 47-74

[Hasło:] Pojęcie, w: Słownik języka polskiego, red. W. Doroszewski, Warszawa 1964, t. 6 , s. 818

Pośpiech A., Pułapka oczywistości. Pośmiertne spisy ruchomości szlachty wielkopolskiej z XVII w., Warszawa 1992

Przewodnik po kognitywistyce, red. J. Bremer, Kraków 2016

Richardson C., Written Texts and the Performance of Materiality, w: Writing Material Culture History, red. A. Gerritsen, G. Riello, London 2015, s. 43-58

Rutkowski J., Historia kultury i próba systematyzacji jej zagadnień, „Kwartalnik Historii Kultury Materialnej" VII, 1959, 1, s. 3-61

Rzeczy i ludzie. Humanistyka wobec materialności, red. J. Kowalewski, W. Piasek, M. Śliwa, Olsztyn 2008

Skubiszewski P., O dwóch podstawowych sposobach uprawiania historii sztuki, „Teksty: teoria literatury, krytyka, interpretacja" 1974, 5(17), s. 57-85

Tandecki J., K. Kopiński, Edytorstwo źródeł historycznych, Warszawa 2014

Teoria a praktyka edycji nowożytnych źródeł w Polsce (XVI-XVIII w.), red. A. Perłakowski, Kraków 2011

Topolski J., Teoria wiedzy historycznej, Poznań 1983

White H., Foucault Decoded. Notes from Underground, „History and Theory” 1973, $1(12)$, s. 23-54

White H., The End of Narrative Historiography, w: Świat historii. Prace z metodologii historii i historii historiografii dedykowane Jerzemu Topolskiemu z okazji siedemdziesięciolecia urodzin, red. W. Wrzosek, Poznań 1998, s. 393-409

White H., Poetyka pisarstwa historycznego, tłum. E. Domańska, M. Loba, A. Marciniak et al., Kraków 2010

Wielowiejski J., Próba systematyki kultury materialnej społeczeństw europejskich W starożytności i średniowieczu, „Kwartalnik Historii Kultury Materialnej” XIX, 1971, 1, s. 189-191

Witek M., Koncepcja pojęć ad hoc jako wytworów interpretacji aktów komunikacyjnych. Analiza krytyczna, w: Pojęcia, red. J. Bremer, A. Chuderski, Kraków 2011, s. $139-172$

Wyczański A., Szlacheckie inwentarze pośmiertne z XVI w. jako źródło do dziejów kultury materialnej w Polsce, „Kwartalnik Historii Kultury Materialnej” II, 1954, 4, s. 691-699

Ziemba A., Sztuka Burgundii i Niderlandów 1380-1500, t. 3, Wspólnota rzeczy. Sztuka niderlandzka i północnoeuropejska 1380-1520, Warszawa 2015 
Konrad Morawski

Instytut Historii Sztuki

Uniwersytet Warszawski

\section{IS A „WORLD OF THINGS" POSSIBLE WITHOUT THINGS? \\ THE PROBLEM OF STUDYING INVENTORIES OF PROPERTY IN ART HISTORY}

\section{Summary}

The paper addresses a problem which traditional art history has thus far ignored, i.e. the examination of items listed in inventories of property. Art historians usually approach concrete works of art to textualize them, while they are helpless confronting items "hidden" behind a text. In the context of the "materiality turn," inventories reveal their paradoxical character since they include "personal" information about individual objects. If one assumes that the inventory is an instrument used to examine the objects listed in it, one must also realize a basic paradox of approaching them via their purely textual representation. A growing interest of art historians in publishing historical sources, in particular inventories, should result in more reflection on the role assigned to texts and things by historiography. To answer the question how items listed in inventories are available to their readers, the author has made references to cognitive linguistics and epistemology, critiques of historical narrativism, and poststructuralism. Such a comprehensive frame of reference made it possible to analyze some problems of the theory of historical source analysis and the editing and publishing of source texts. A comparison of art history and history of material culture resulted in defining the expectations and limitations related to the study of property inventories conducted by both disciplines. The experience of object analysis, which is a key prerequisite of interpretation, has been described in reference to three cognitive terms: concepts, exemplars, and invariants. The scholar trying to use all the available sources to reach the object itself must take advantage of all his/her experience. Analysis is possible only in a context, while the meaning of concepts, i.e. brief entries about individual items, can be discovered only in a complex system of semiotic reference. Apparently, such analysis can never be objective.

Keywords:

thing, inventory of property, text, inventory analysis, art history 